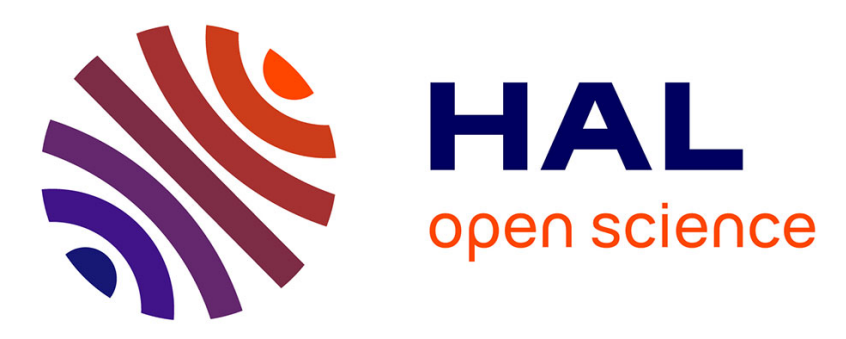

\title{
Analysis of ground rice straw with a hydro-textural approach
}

\author{
Santi Chuetor, Abdellatif Barakat, Xavier Rouau, Thierry Ruiz
}

\section{To cite this version:}

Santi Chuetor, Abdellatif Barakat, Xavier Rouau, Thierry Ruiz. Analysis of ground rice straw with a hydro-textural approach. Powder Technology, 2016, 310, pp.74-79. 10.1016/j.powtec.2016.12.072 . hal-01604805

\section{HAL Id: hal-01604805 https://hal.science/hal-01604805}

Submitted on 25 May 2020

HAL is a multi-disciplinary open access archive for the deposit and dissemination of scientific research documents, whether they are published or not. The documents may come from teaching and research institutions in France or abroad, or from public or private research centers.
L'archive ouverte pluridisciplinaire HAL, est destinée au dépôt et à la diffusion de documents scientifiques de niveau recherche, publiés ou non, émanant des établissements d'enseignement et de recherche français ou étrangers, des laboratoires publics ou privés. 


\section{Accepted Manuscript}

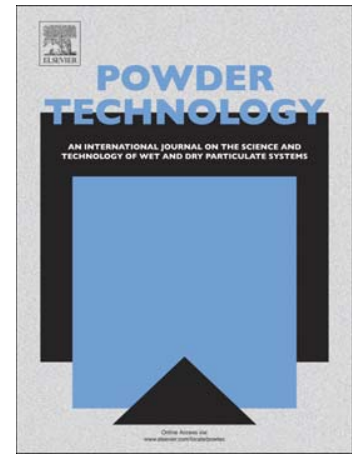

Analysis of ground rice straw with a hydro-textural approach

Chuetor Santi, Barakat Abdellatif, Rouau Xavier, Ruiz Thierry

PII: $\quad$ S0032-5910(16)30952-4

DOI: $\quad$ doi: $10.1016 /$ j.powtec.2016.12.072

Reference: $\quad$ PTEC 12220

To appear in: $\quad$ Powder Technology

Received date: 26 September 2016

Revised date: 16 December 2016

Accepted date: 23 December 2016

Please cite this article as: Chuetor Santi, Barakat Abdellatif, Rouau Xavier, Ruiz Thierry, Analysis of ground rice straw with a hydro-textural approach, Powder Technology (2016), doi: $10.1016 /$ j.powtec.2016.12.072

This is a PDF file of an unedited manuscript that has been accepted for publication. As a service to our customers we are providing this early version of the manuscript. The manuscript will undergo copyediting, typesetting, and review of the resulting proof before it is published in its final form. Please note that during the production process errors may be discovered which could affect the content, and all legal disclaimers that apply to the journal pertain. 


\title{
Analysis of Ground Rice Straw with a hydro-textural approach
}

\author{
CHUETOR Santi ${ }^{1}$, BARAKAT Abdellatif ${ }^{2}$, ROUAU Xavier ${ }^{2}$, RUIZ Thierry $^{2 *}$ \\ ${ }^{1}$ Faculty of Science, Chandrakasem Rajabhat University, Chatuchak, Bangkok 10900, \\ Thailand \\ ${ }^{2}$ UMR IATE 1208 CIRAD/INRA/Montpellier SupAgro/Université Montpellier - 2 \\ Place Pierre Viala, 34060 Montpellier cedex 5, France.
}

Corresponding author : Tel. +33 4671446 17, e-mail : thierry.ruiz@ umontpellier.fr

\begin{abstract}
The lignocellulosic material contained in agricultural residues like straws, represents a resource with many points of biomolecular interest but their extraction is subject to a succession of treatments highly energy-consuming and generating effluents. Due to the strength of the supramolecular structure of the lignocellulosic matrix at various levels, it is difficult to improve the efficiency of separation processes for these materials. The utilization of biomass constituents often requires pretreatment, which is a crucial step in the separation into constituents. The rice straw must firstly be fractionated by grinding, which can also require pretreatment to improve efficiency. The question arises as to how best to identify and model the mechanisms involved in the grinding process with or without pretreatment. The aim of this study was to complete the characterization of the grinding process using a hydro-textural approach applied to biopowders to help with identification of the mechanisms involved. Experimental trials were conducted with rice straw through several milling steps, which led to decreasing particle sizes. The physical properties (density, cohesion, coefficient of friction, ability to flow) were characterized for some of the obtained powders, which were then described with a hydro-textural diagram. The results reveal that the breakdown process led to a "loss of porosity" regardless of the size of the powder particles. The fragmentation seemed to be located in
\end{abstract}


the "zones of stronger porosities". These structures containing residual water, decreased weakly with grinding. Assuming that the water was located within cells of the straw (intracellular water), given the power law, which correlates compactness to median diameter $\left(d_{50}\right)$, we introduced a characteristic size, which corresponds to the physical limit of optimal grinding. Its value, calculated from the model, is nearly equal to the cell wall thickness: $\lim _{\phi \rightarrow 1} d_{50}=e_{\text {cell. }} \sim 2 \mu m$.

Keywords: Lignocellulose, Biomass, Rice straw, Grinding, Hydro-textural description.

\section{Introduction}

Utilization of lignocellulosic material for bioenergy has been studied for the last 30 years. A number of lignocellulosic biomasses such rice straw (RS) are considered a renewable source for biofuel production such as bioethanol, biohydrogen as well as biogas (Wyman, 1994). Bio-based fuels and products may contribute to energy supplies and economic development. Indeed, RS contains biomolecules such as cellulose, hemicellulose and lignin that can be converted into multiple bio-based products (Sun and Cheng, 2002). In order to valorize RS, a biorefinery process must be developed to recover biomolecules of interest such as fermentable sugars that can be converted into biofuel (Wang, Wang et al. 2011). Biorefinery is a global process aiming to convert all constituents of biomass to bio-products as well as bioenergy. Nevertheless, the structural heterogeneity and complexity of RS such as cellulose crystallinity, accessible surface area, porosity, and matrix polymer, hinder accessibility to enzymatic release of fermentable sugars. Despite numerous studies having been conducted, an understanding of the optimal processes to valorize RS is still inadequate because of competing effects including the physical properties of RS material and mass transfer.

Several factors also affect enzymatic digestibility including the chemical composition and physical features of RS (Barakat, Chuetor et al. 2014). In order to facilitate the recovery of constituents of interest, pretreatment of the untreated material is an inevitable preliminary step to facilitate biorefinery (Taherzaeh et al. 2004; Barakat, de 
Vries et al. 2013). Various pretreatments broadly lead to fractionation and or alteration of RS structure. These processes have been generally divided into different categories; physical, chemical, physicochemical and biological as well as their combinations. Pretreatment is required in order to make biomolecules more accessible in subsequent steps for bioconversion. The objective of the pretreatment process depends on the material structure. For instance, physical pretreatment, like mechanical comminution, is considered a crucial process in biorefinery. The objective here is to reduce particle size but at the same time rupture the plant cell wall and cause dissociation of the tissues. Overall, this contributes to the matter transfer rate. The physical characteristics of the bio-material are considered barriers to enzymatic accessibility. Accordingly, the objective of mechanical pretreatment by grinding is to reduce particle size and the cellulose crystallinity to eventually change the shape, increase bulk density (porosity) and the accessible surface area and to improve flow properties. As is well known, a highly accessible surface area leads to increased kinetics of enzymatic reactions (Schell and Harwood 1994; Bitra, Womac et al. 2009). Also, particle size reduction by grinding allows a decrease in cellulose crystallinity, as well as polysaccharide depolymerization, consequently increasing enzymatic hydrolysis yields (Barakat, de Vries et al. 2013). Moreover, particle size reduction modifies the mechanical behavior of the resulting powdered product, which has consequences for its flow properties. RS is broadly considered an elasto-plastic material with an irregular form (Annoussamy, Richard et al. 2000; Muller, 2003).

Despite the effectiveness of mechanical pretreatment by grinding being well known, how the chemical composition is distributed and how the cell wall structure of RS is ruptured during grinding still remains largely unknown.

The physical, mechanical as well as rheological characterizations of RS powder are considered relevant parameters to describe the deconstruction of this material. Moreover, how to follow and model the dissociation mechanism during grinding requires a conceptual and multidisciplinary approach.

The current study aims to characterize the raw material state without chemical pretreatment during a grinding process using a hydro-textural approach defined for granular materials (Ruiz et al., 2005 and 2011). An examination of hydro-textural parameters will allow depiction of the state of the powders after each grinding step. 


\section{Materials and Methods}

\subsection{Raw material and grinding technologies}

Rice straw (RS) was obtained from a local farm in the Languedoc-Roussillon region in the south of France. The straw was dried beforehand and its moisture content determined to correspond to the hygroscopic conditions of temperature and relative humidity of the laboratory. The material is comprised of fragments of dry straw of onecentimeter length.

Three different technologies were used to produce different ranges of fractions: knife milling (KM) for a coarse fraction, high-speed impact milling (IM) (UPZ pallet milling) for a fine fraction and vibro-ball milling (VBM) for an ultrafine fraction (Figure1). Knife milling allows a coarse fraction to be obtained by the impact between a knife and the RS, which then was accelerated through selected sieves. In this study, sieves of $2 \mathrm{~mm}$ and $6 \mathrm{~mm}$ were used for coarse milling. After knife milling, the RS was then milled with a UPZ Pallet (Hosokawa Alpine) to obtain a finer fraction using $0.1 \mathrm{~mm}$ and $0.5 \mathrm{~mm}$ sieves. This type of milling uses a hammer rotor and a screen sieve, which induces impact between particles and a rotor in high-speed rotation. The particles passed through the sieve when their size was less than the sieve size of $0.1 \mathrm{~mm}$ and $0.5 \mathrm{~mm}$ in this study. Finally, vibro-ball milling was applied to RS to obtain an ultrafine fraction with particle size of less than $100 \mu \mathrm{m}$. Vibro-ball milling consists of grinding jars which perform oscillations in a horizontal position. The vibrations cause the ball to impact the particles with high energy and frequency. Also, the movement of the grinding jars combined with the movement of the balls results in intensive mixing of the particles. In this case, grinding was performed at room temperature for either 20 or 40 minutes. The respective fractions obtained were of $50 \mu \mathrm{m}$ and $25 \mu \mathrm{m}$.

After the successive grinding/milling processes were applied, 6 different samples named according to the type of process and/or the sizes of the particles were obtained. The product resulting from (i) knife milling with a $2 \mathrm{~mm}$ sieve was labeled $\mathrm{KM}_{2}$ and with a $6 \mathrm{~mm}$ sieve $\mathrm{KM}_{6}$; from (ii) UPZ milling using a $0.1 \mathrm{~mm}$ sieve was named $\mathrm{IM}_{0.1}$, and with a $0.5 \mathrm{~mm}$ sieve, $\mathrm{IM}_{0.5}$; and (iii) powders milled by vibro-ball milling with a median 
diameter of about $40 \mu \mathrm{m}$ were named $\mathrm{VBM}_{40}$, and with a median diameter near $20 \mu \mathrm{m}$, $\mathrm{VBM}_{20}$.

\subsection{Methods}

Particle size measurement was performed using two different technologies: sieving for straw fragments $\left(\mathrm{KM}_{2}\right.$ and $\left.\mathrm{KM}_{6}\right)$ and laser granulometer (Malvern Instruments Ltd., United Kingdom) for particles with a size less than $2 \mathrm{~mm}$ including $\mathrm{IM}_{0.1}, \mathrm{IM}_{0.5}, \mathrm{VBM}_{40}$ and $\mathrm{VBM}_{20}$. For each powder the size distribution curve was determined. The median diameter (d50) and the span defined by (d90-d10)/d50 are both criteria held to describe their distributions.

SEM and aspect ratio. Scanning electron microscopy analysis (SEM) was performed to determine the structural changes, morphological structure and surface characteristics of ground RS. Ground RS was prepared by attaching it on a specimen stub. The sample was then heated with methane to eliminate the electrostatic effect prior to imaging with scanning electron microscope (SEM Hitachi S4800). The converted SEM images were then treated by Image $J \circledR$ software to deduce the powder sizes of a representative population of particles $(-30)$. The aspect ratio was then determined by calculating the ratio of maximum and minimum length of each sample $\left(1_{\min } / l_{\max }\right)$. For each ground powder sample, distribution of aspect ratios was represented by the mean value and the standard deviation $(\sigma)$.

Hydro-textural characterization. Grinding processes led not only to many changes in external properties, especially morphology and particle size (particle size distribution and shape) but also affected the internal so-called, hydro-textural properties. Ruiz et al. (2011) developed an approach to describe all internal and external property changes of wet granular material due to transformation processes (particle size, compactness and moisture content). This approach consists of the construction of a hydro-textural diagram, which represents the evolution of compactness and moisture content. In addition, Ruiz et al. have defined hypotheses on this approach applied in the current study, in particular, the effects of grinding processes on powder characteristics. 
RS powder is typical of a solid-liquid-gas three-phase system. Each phase can be generally defined by its real density symbolized as $\rho^{*}$. The real density for the solid phase is $\rho_{s}^{*}=m_{s} / V_{s}$, measured using a Nitrogen Pycnometer. The macroscopic state of the material can be defined by real density and three measured parameters: granular media volume $(V)$, internal water mass $\left(m_{h}\right)$ and dry mass $\left(m_{s}\right)$. The humid and dry masses were measured respectively with a precision balance before and after drying in an oven at a temperature of $104^{\circ} \mathrm{C}$ for 2 hours. The volume of the powders was measured using a hydrostatic balance with paraffin oil, which ensures the wetting of powders without penetration. Moisture content $w=m_{e} / m_{s}$, compactness $\phi=V_{s} / V$ and degree of saturation $S=V_{e} /\left(V-V_{S}\right)$, were calculated from experimental measurements. For the purpose of describing the macroscopic characteristics of the system, these parameters are normally necessary and sufficient.

In addition, in order to track all relevant parameters $(\phi, w)$ during the grinding and milling processes, a hydro-textural diagram was established. The upper limit of the diagram is bound by the saturation curve: $\phi_{s a t}^{-1}=1+d_{s}^{*} w$ (where $d_{s}^{*}$ represents dry density solid). Beyond this curve, the system loses physical realism as its state becomes mixed. The saturation curve represents the maximum moisture content that can be absorbed by the available pores in the liquid phase (i.e. solid « saturated » by liquid).

Mechanical properties. Compression tests and shearing tests of the milled RS powders were performed using an FT4 powder rheometer (Freeman Technology, Worcestershire, UK). The measurements were carried out in a cylindrical glass cell (diameter $=50 \mathrm{~mm}$; height $=50 \mathrm{~mm}$ ). The RS sample was then carefully introduced into the measuring cell with a broad spatula and then submitted to a specific conditioning procedure that aims to ensure an initial uniform packing state from one test to another. After this preconditioning step, the RS sample was subjected for 60 seconds to a $15 \mathrm{kPas}$ preconsolidation step carried out using a $48 \mathrm{~mm}$ micro-perforated piston moving vertically. The top glass cell was then withdrawn together with the excess powder in order to level the pre-consolidated sample surface. After RS pre-conditioning was completed, shear stress $(\boldsymbol{\tau})$ was applied at increasing pressure $(\boldsymbol{\sigma})$. Mohr circles were then drawn according to Coulomb's law: $\boldsymbol{\tau}=\boldsymbol{\mu} \boldsymbol{\sigma}+\boldsymbol{C}$, which allowed determination of the apparent friction coefficient $(\boldsymbol{\mu})$ and the apparent cohesion $(\boldsymbol{C})$ for each powder. 


\section{Experimental results and discussion}

\subsection{Particle size distribution and powder morphologies}

Particle size is the parameter directly impacted by the grinding and milling process resulting from fragmentation. Table 1 represents the characteristics of particles obtained with each different process of grinding and milling. Each distribution is monodispersed, so the particle size distribution is characterized by the median diameter $\left(\mathrm{d}_{50}\right)$ and the span calculated by the equation: $\left(d_{90}-d_{10}\right) / d_{50}$. It can be seen that a diameter of $\mathrm{d}_{50}$ decreased with increasing energy from the grinding/milling process. Moreover, the smaller the particle size, the wider the size distribution. Figure $2 \mathrm{a}$ illustrates the logarithmic dependence of these factors $\left(\operatorname{span} \propto-\ln \left(d_{50}\right)\right)$. This result indicates that particle size reduction comes along with an increase in polydispersity. It is assumed that this gain in polydispersity does not improve the flow properties of powders because of its heterogeneity.

In order to investigate the shape of ground particles, a SEM was used to analyze the distribution of aspect ratios. The experimental results showing the powder morphologies as observed with the SEM are presented in Figure 3. The results show that fibrous forms were more important for the big particles than the smaller. This indicates that the initial RS was mostly in fibrous form when it was chopped with different grades of knife milling (Fig. 3a and 3b). This kind of milling results only in size reduction. On the other hand, impact milling with 0.5 and $0.1 \mathrm{~mm}$ screens respectively, also affects the morphology of RS matter. As seen in Figure 3c, Figure 3d, Figures $3 e$ and $3 f$, the particles resulting from milling with $\mathrm{VBM}_{20}$ and $\mathrm{VBM}_{40}$ are relatively more destroyed compared to the particles derived from the other two milling techniques.

In order to evaluate the extent of change in the particles resulting from different mechanical processes, the aspect ratios were calculated as reported in Figure $2 b$. Powders $\mathrm{KM}_{6}, \mathrm{KM}_{2}, \mathrm{IM}_{0.5}$ and $\mathrm{IM}_{0.1}$, were rather more stable in a fibrous form which varied between 0.4 and 0.45 . Below $100 \mu \mathrm{m}$, the aspect ratio increased reaching a maximum at 0.63 when ground with $\mathrm{VBM}_{40}$. With $\mathrm{VBM}_{40}$ grinding at this size, particle shape tended to be more spherical. From 50-100 $\mu \mathrm{m}$, the particles were likely to approximate the size of the plant cell wall. It is now known that grinding breaks down 
these structures into fragments, the shape of which become less and less fibrous. This result indicates that these fibrous cells were cut perpendicularly to the larger size.

\subsection{Hydro-textural analysis}

The hydro-textural description concerns the parameters $(\phi, w, S)$. All RS characteristics are presented in Table 2, which shows that moisture content decreases with decreasing particle size (Fig. 4a). However, there is water loss, which might be due to heating during the grinding operation, but this moisture content reduction is not significant. The particle size reduction from $900 \mu \mathrm{m}$ to $26 \mu \mathrm{m}$, (approx. 97\%) is more significant while water removal only accounts for about $11 \%$. Thus, the grinding operation not only breaks plant cell tissue down but also decreases the amount of water contained in the material.

This decrease in moisture content obviously affects the degree of saturation directly (Fig. 4a), which increases with decreasing particle size. This variation is explained by the effect of size reduction, which corresponds to the rise of powder density from about $1.2 \mu \mathrm{m}$ to about $1.7 \mu \mathrm{m}$. This indicates that (i) RS powders are in an unsaturated state as a consequence of drying and (ii) the more particles are ground, the denser they become as confirmed by the increase in compactness (Table 2). This unsaturated state tends to greater saturation with size reduction: $\lim _{d_{50} \rightarrow 0} S=1$ (Fig. 4a). Hence, this indicates that when particle size is reduced, there are less void zones in the porous RS leading to water content staying almost constant, which consequently increases the degree of saturation. Most water remains contained in the cells or their fragments as a compact and saturated medium such that the grinding operation reduces the voids in the material. Additionally, an increase in compactness indicates that the local mechanism is effective in breaking down the straw at the level of void localization. Moreover, the compactness of RS powders correlates with median diameters according to the power law: $\phi=$ $\left(\frac{d_{50}}{d_{50}^{\circ}}\right)^{S}$, with $s$ an exponent related to the geometry of the straw and $d_{50}^{\circ}$ the median size of the smallest structure which could be ground by this process. This, in turn, corresponds to: $d_{50}^{\circ}=\lim _{\phi \rightarrow 1} d_{50}$ and is equal to $\sim 2 \mu \mathrm{m}$. This power law has fit experimental data for more than two decades with a robust correlation $\left(\mathrm{R}^{2}=0.97\right)$ (Fig. 4b). The order of magnitude of $d_{50}^{\circ}$ is comparable to the thickness of the RS cells 
shaped in a fiber form. This characteristic is consistent with the fact that the cells should be preferentially cut in the transverse plane rather than in a longitudinal orientation. It can also be seen that with size reduction, the extent of size distribution widens (Table 2). The presented relation between the mean value of compactness and median diameter indicates a correlation between size fluctuations and compactness fluctuations, which may be worth studying in future, but quantification of compactness fluctuations has not yet been undertaken.

The power law allows us to interpret straw grinding as a fractal deconstruction mechanism (Dang and Nguyen, 2007) whose fractal dimension can be determined by the equation: $s=D_{f}-3$, with $D_{f}$ the fractal dimension of the considered object equal to 2.354 in this case ( 3 is the space dimension including the object). This result could be linked with the theoretical fractal geometry of straw, provided that the morphogenesis of RS follows such a growth process (Mandelbrot, 1982; Gardiner et al., 2012). The structures involved demonstrate that the histology of straw could therefore be agented with hierarchized void levels (from cells to fibers to epidermal system).

\subsection{Mechanical properties}

The mechanical characterization of the powder obtained from grinding the RS was determined in a shear cell rheometer (FT4 powder rheometer). From Mohr circles, the Coulomb straight line allows us to define the apparent friction coefficient and the apparent cohesion. The apparent cohesion and friction coefficient are measured at the pallet scale not at the particle scale. Generally, in the literature, lignocellulose powder materials have been poorly studied.

Concerning the evolution of the coefficient of friction (Fig. 5a) and cohesion (Fig. 5b) with the size of powder particles, a surprising dependency of the coefficient of friction and cohesion can be observed. The coefficient of friction has the smallest value $(\boldsymbol{\mu} \approx 0.25)$ for the straw cut by milling, which is smaller than other powders while cohesion has a higher value $(C \approx 2 \mathrm{kPa})$, which is not significantly different from the other powders. Thus, this can be considered a low cohesive powder. Particle size reduction increased the coefficient of friction to a maximum then started to decrease for the smallest particle size powders. The cohesion decreases to a minimum, which 
corresponds to the size where the coefficient of friction reaches its maximum and then, for fine powders $\left(d_{50} \leq 100 \mu \mathrm{m}\right)$, increases. Grinding operations are normally able to increase specific surface areas that consequently increase cohesion. A possible explanation for this counterintuitive behavior is, for powders ground to $100 \mu \mathrm{m}$, the particles are such small fibers as to render physicochemical and steric interactions insignificant. The aspect ratio collaborates with the fiber shape of the particles (Fig. 5b). The physicochemical interactions are not significant in considering the steric entanglement of fibers and at the same time, particles are attracted to others due to a relatively low flow threshold. The particles are thus attached by mechanical force due to geometric complexity. Particles below $100 \mu \mathrm{m}$ become more and more spherical (Fig. 2b) which entails a decrease in steric interactions. Cohesion then increases by a gain of specific surface area, which promotes attractive interactions.

\section{Conclusion}

The current study presented new characterization methods for the analysis of lignocellulosic powder using different technologies allowing for the characterization of the structural organization of the lignocellulosic matrix and its fractionation. A hydrotextural approach has been used to describe the wet granular state of rice straw resulting from different grinding operations. Upon grinding, particles become smaller, more sphericaland more compact, as well as more saturated, which improves rice straw sensitivity to further enzymatic hydrolysis and fermentation. A power law was proposed to describe the relation between size reduction and increase in compactness. This model highlights the theoretical value of applying a limit in grinding size, which seems to correspond to the thickness of the rice straw cell wall. This value is in an order of magnitude consistent with the process limits generally observed for this kind of material (Barakat et al., 2013). The mechanical studies have shown changes in cohesion and friction properties during the grinding process linked to aspect ratio evolution. The key parameters identified in this study are further affected by the combination of grinding with other chemical or physical-chemical pretreatments of the untreated material (Barakat et al., 2014). These pretreatments used to improve technical and economic efficiency of biorefinery processes (Chuetor et al., 2015), could be analysed by the same 
approach to follow the evolution of the powder characteristics throughout their transformations.

\section{References}

Annoussamy, M., Richard, G., Recours, S. and Guerif, J. 2000. Change in mechanical properties of wheat straw due to decomposition and moisture. Applied Engineering in Agriculture, 16, 657-664.

Barakat, A., De vries, H. and Rouau, X. 2013. Dry fractionation process as an important step in current and future lignocellulose biorefineries: A review. Bioresource Technology, 134, 362-373.

Barakat, A., Chuetor, S., Monlau, F., Solhy, A. and Rouau, X. 2014. Eco-friendly dry chemo-mechanical pretreatments of lignocellulosic biomass: Impact on energy and yield of the enzymatic hydrolysis. Applied Energy, 113, 97-105.

Bitra, V. S. R., Womac, A. R., Chevanan, N., Miu, P. I., Igathinathane, C., Sokhansanj, S. and Smith, D. R. 2009. Direct mechanical energy measures of hammer mill comminution of switchgrass, wheat straw, and corn stover and analysis of their particle size distributions. Powder Technology, 193, 32-45.

Chuetor, S., Luque, R., Barron, C., Solhy, A., Rouau, X. and Barakat, A. 2015. Innovative combined dry fractionation technologies for rice straw valorization to biofuels Green Chemistry, 17, 2, 926-936.

Dang, V. Q., and Nguyen, K. L. 2007. A universal kinetic equation for characterising the fractal nature of delignification of lignocellulosic materials. Cellulose, 14, 153-160.

Gardiner, J., Overall, R., and Marc, J. 2012. Plant microtubule cytoskeleton complexity: microtubule arrays as fractals. Journal of Experimental Botany, 63, 2, 635-642.

Mandelbrot, B. 1982. The Fractal Geometry of Nature, Freeman, San Francisco, CA, USA.

Mani, S., Tabil, L. G. and Sokhansanj, S. 2004. Grinding performance and physical properties of wheat and barley straws, corn stover and switchgrass. Biomass and Bioenergy, 27, 339-352. 
Moghddam, P. R. and Wilman, D. 1998. Cell wall thickness and cell dimensions in plant parts of eight forage species. Journal of Agricultural Science, 131, 59-67.

Müller, J. A. 2003. Comminution of organic material. Chemical Engineering \& Technology, 26, 207-217.

Nguyen, D. H., Azéma, E., Radjai, F. and Sornay, P. 2014. Effect of size polydispersity versus particle shape in dense granular media. Physical Review E, 90.

Rondet, E., Delalonde, M., Ruiz, T. and Desfours, J.P. 2008. Hydro-textural and dimensional approach for characterising wet granular media agglomerated by kneading. Chemical Engineering Research \& Design, 86, 560-568.

Ruiz, T., Delalonde, M., Bataille, B., Baylac, G. and Dupuy de Crescenzo, C. 2005. Texturing unsaturated granular media submitted to compaction and kneading processes. Powder Technology, 154, 43-53.

Ruiz, T., Rondet, E., Delalonde, M. and Desfours, J.P. 2011. Hydro-textural and consistency surface states of humid granular media. Powder Technology, 208, 409-416.

Schell, D. J. and Harwood, C. 1994. Milling of lignocellulosic biomass - results of pilot scale testing. Applied Biochemistry and Biotechnology, 45-6, 159-168.

Shaebani, M. R., Madadi, M., Luding, S. and Wolf, D. E. 2013. Effect of Size Polydispersity on Micromechanical Properties of Static Granular Materials. Powders and Grains 2013, 1542, 875-878.

Silva, G. G. D., Couturier, M., Berrin, J.-G., Buléon, A. and Rouau, X. 2012. Effects of grinding processes on enzymatic degradation of wheat straw. Bioresource Technology, 103, 192-200.

Sun, Y. and Cheng, J. Y. 2002. Hydrolysis of lignocellulosic materials for ethanol production: a review. Bioresource Technology, 83, 1-11.

Taherzaeh, J., M., and Nikilasson, C., 2004. Ethanol from lignocellulosic materials: Pretreatment, acid and enzymatic hydrolyses, and fermentation, Cary, Nc USA, Oxford University Press.

Wang, M., Wang, J. and Tan, J. X. 2011. Lignocellulosic Bioethanol: Status and Prospects. Energy Sources Part a-Recovery Utilization and Environmental Effects, 33, 612-619.

Wyman, C. E. 1994. Alternative fuels from biomass and their impact on carbon-dioxide accumulation. Applied Biochemistry and Biotechnology, 45-6, 897-915. 
Yang, Y., Ji, G. Y., Xiao, W. H. and Han, L. J. 2014. Changes to the physicochemical characteristics of wheat straw by mechanical ultrafine grinding. Cellulose, 21, 32573268 .

\section{Acknowledgment}

The authors would like to thank Mr. Cot from the European Institute of Membranes of Montpellier for the realization of the SEM images. We would also like to thank the Ministry of Science and Technology of Thailand and the Franco-Thaï scholarship for providing financial support for this study. 


\section{List of the figures}

Figure 1. Particle size reduction process diagram.

Figure 2. Variations of powder properties with the size for each grinding process.

-a) Span of the distribution size. -b)Average aspect ratio of particles.

Figure 3. Illustration of each powder fractions by SEM pictures. - a) powder $\mathrm{KM}_{6}-\mathrm{b}$ ) powder $\mathrm{KM}_{2}-\mathrm{c}$ ) powder $\mathrm{IM}_{0.5}-\mathrm{d}$ ) powder $\mathrm{IM}_{0.1}-\mathrm{e}$ ) powder $\mathrm{VBM}_{20}-\mathrm{f}$ ) powder $\mathrm{VBM}_{40}$.

Figure 4. Variations of hydrotextural properties of particles with the size for each grinding process. -a) $\square$ Moisture content and $\bullet$ degree of saturation. -b) Compactness.

Figure 5. Variations of mechanical properties according to Coulomb criterion with the size for each grinding process. -a) Coefficient of friction. -b) Cohesion. 


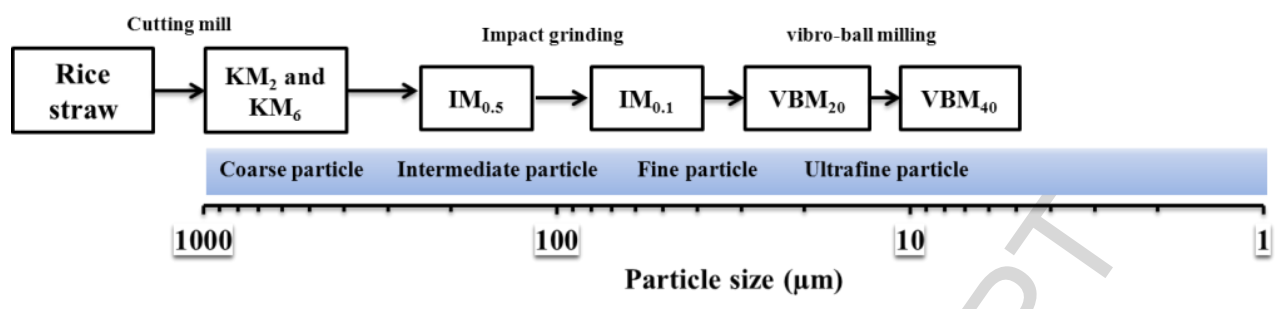

Figure 1. Particle size reduction process diagram. 

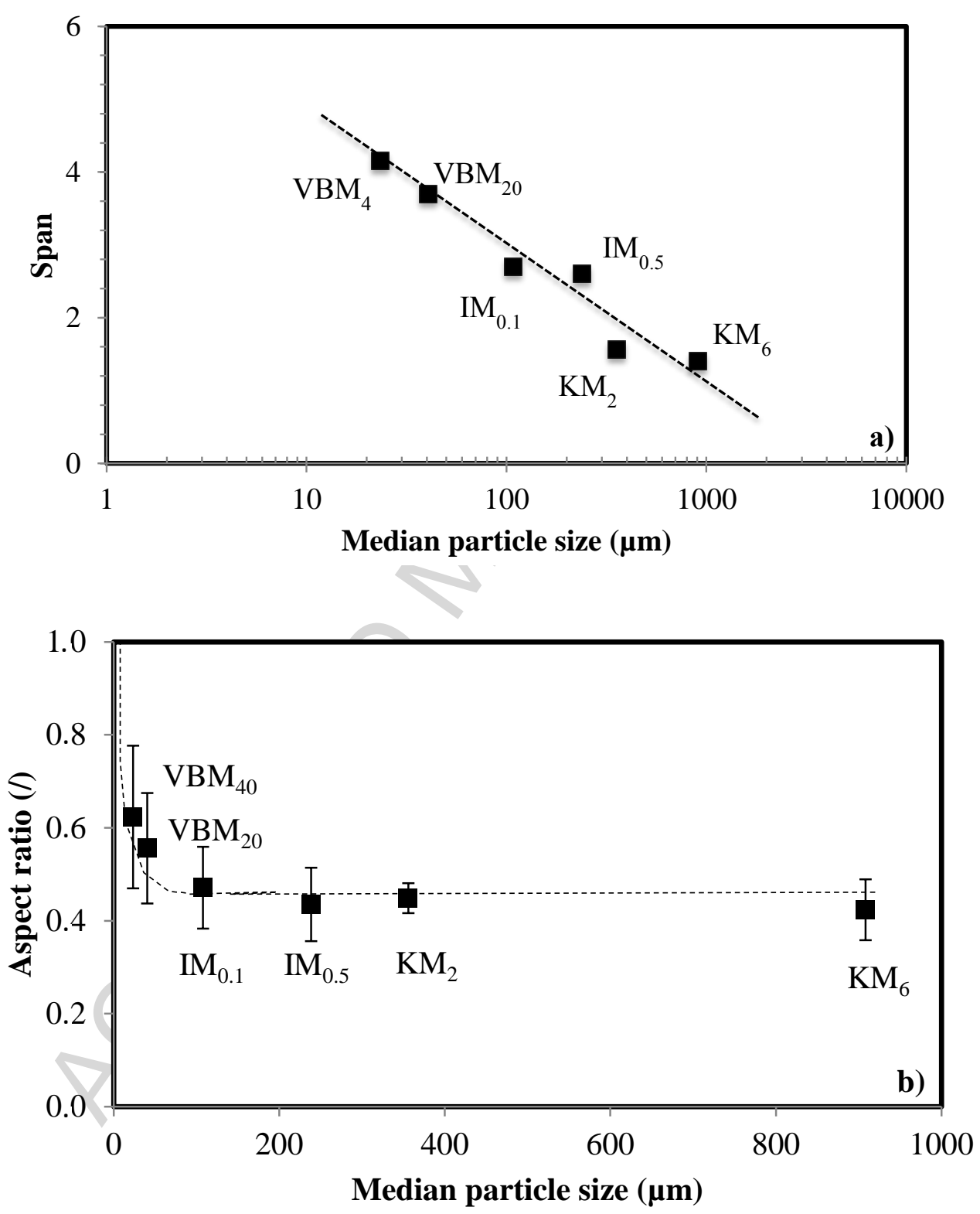

Figure 2. Variations of powder properties with the size for each grinding process.

-a) Span of the distribution size. -b)Average aspect ratio of particles. 


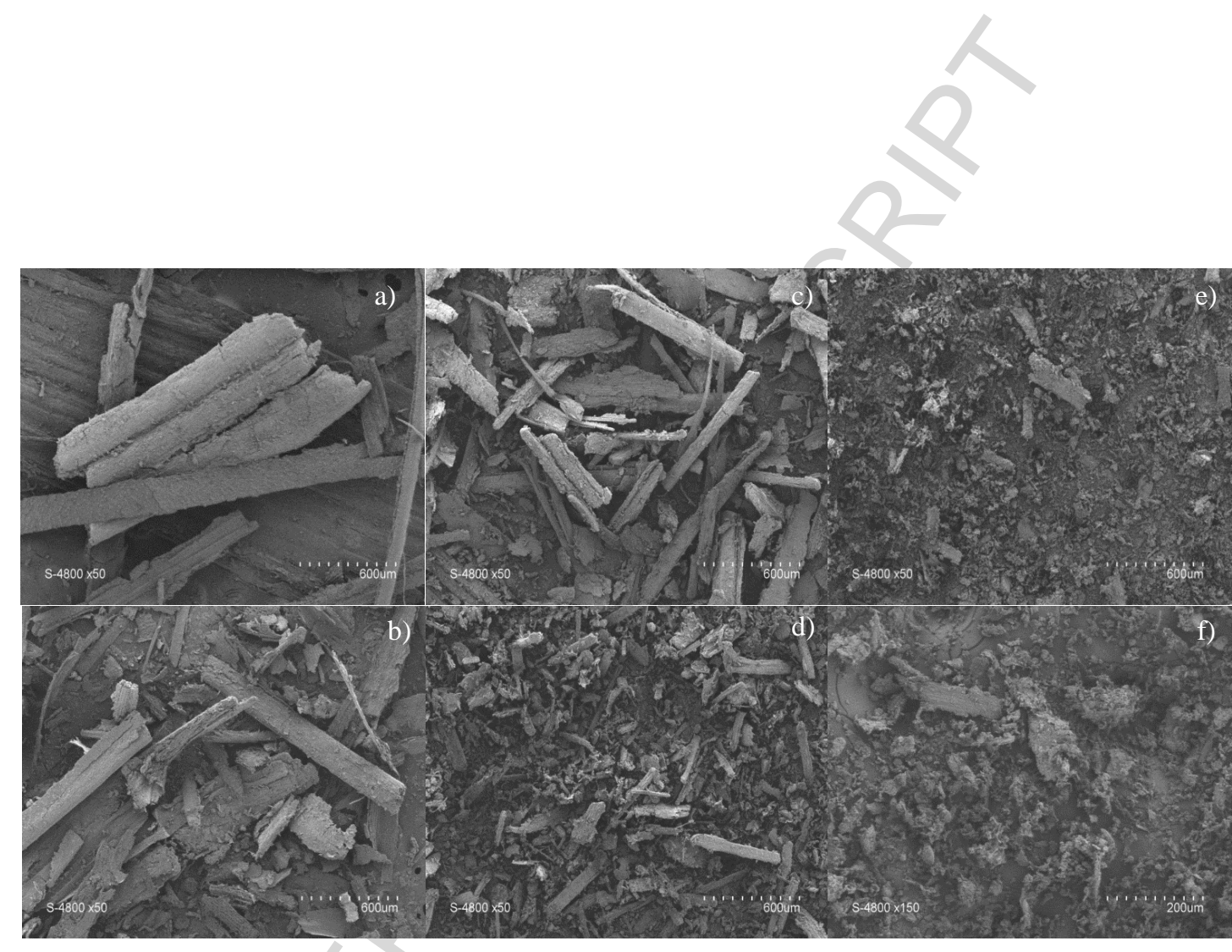

Figure 3. Illustration of each powder fractions by SEM pictures. - a) powder $\mathrm{KM}_{6}-\mathrm{b}$ ) powder $\mathrm{KM}_{2}-\mathrm{c}$ ) powder $\mathrm{IM}_{0.5}-\mathrm{d}$ ) powder $\mathrm{IM}_{0.1}-\mathrm{e}$ ) powder $\mathrm{VBM}_{20}-\mathrm{f}$ ) powder $\mathrm{VBM}_{40}$. 

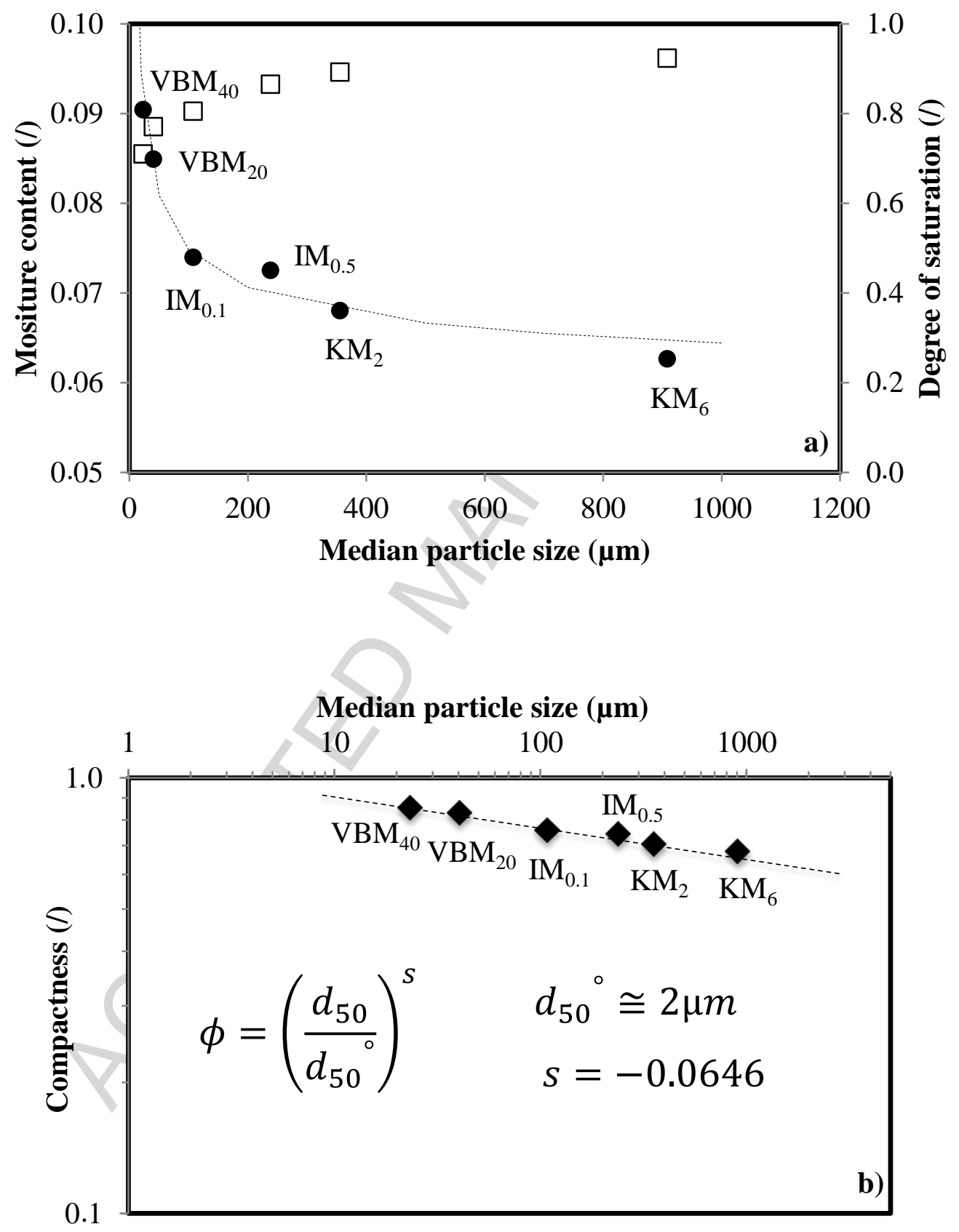

Figure 4. Variations of hydrotextural properties of particles with the size for each grinding process. -a) $\square$ Moisture content and $\bullet$ degree of saturation. -b) Compactness. 

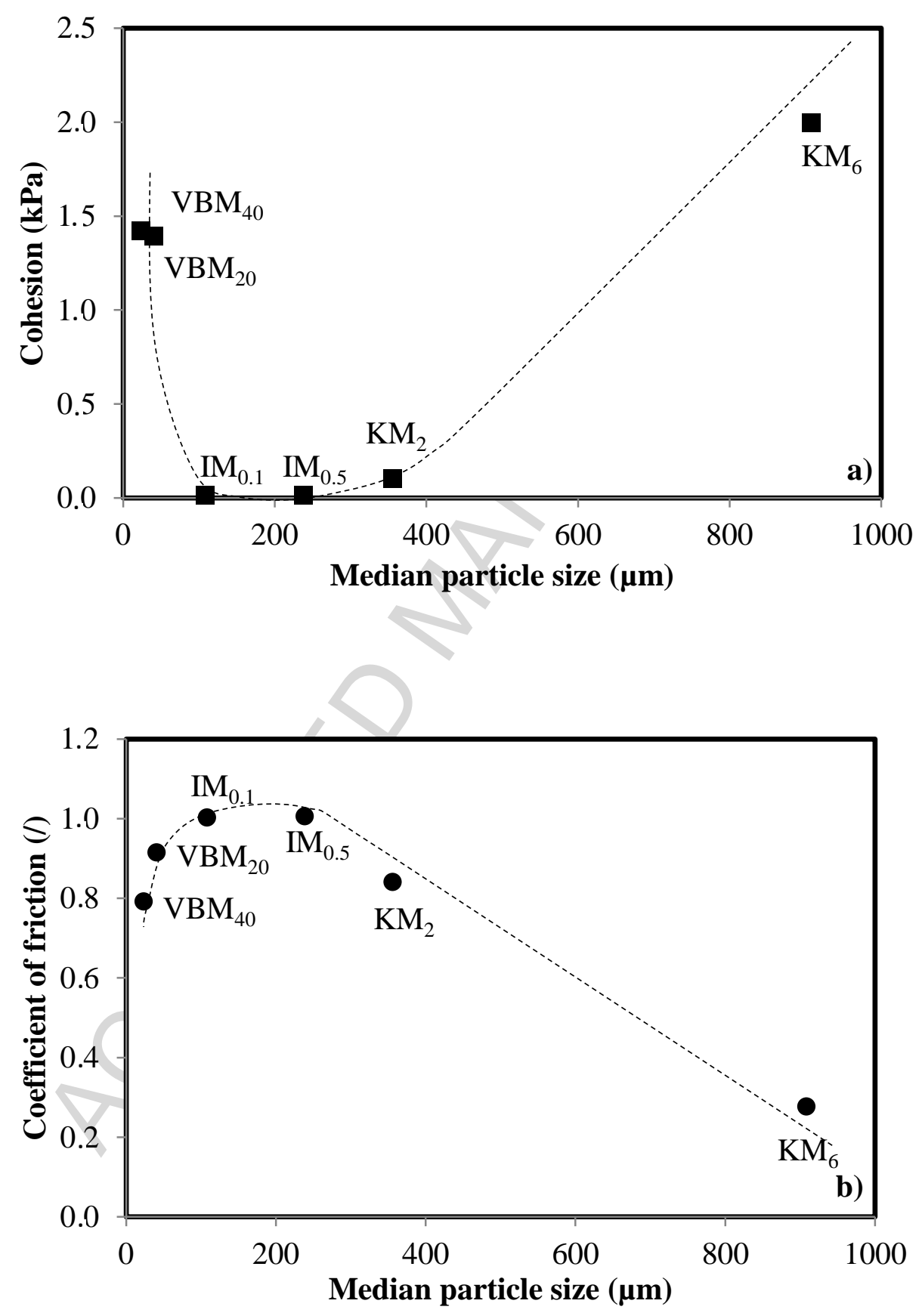

Figure 5. Variations of mechanical properties according to Coulomb criterion with the size for each grinding process. -a) Cohesion. -b) Coefficient of friction. 


\section{List of the tables}

Table1. Values of physical properties of powders obtained after grinding process.

Table2. Values of hydro-textural and density parameters obtained after grinding process. 
Table1. Values of physical properties of powders obtained after grinding process.

\begin{tabular}{rccccc}
\hline & & & & & \\
Grinding techniques & Sample & $\mathrm{d}_{50}(\mu \mathrm{m})$ & SPAN & Aspect ratio & $\sigma$ \\
& & & & $\left(1_{\text {min }} / 1_{\text {max }}\right)$ & \\
& & & & & \\
\hline & $\mathrm{KM}_{6}$ & 908 & 1.404 & 0.424 & 0.065 \\
Knife milling (KM) & $\mathrm{KM}_{2}$ & 356 & 1.559 & 0.448 & 0.032 \\
& $\mathrm{IM}_{0.5}$ & 238 & 2.603 & 0.435 & 0.079 \\
\hline & $\mathrm{IM}_{0.1}$ & 108 & 2.704 & 0.471 & 0.088 \\
\hline Impact milling (IM) & $\mathrm{VBM}_{20}$ & 46 & 3.699 & 0.556 & 0.119 \\
& $\mathrm{VBM}_{40}$ & 26 & 4.151 & 0.623 & 0.153 \\
\hline
\end{tabular}


Table2. Values of hydro-textural and density parameters obtained after grinding process.

\begin{tabular}{cccccc}
\hline \multirow{2}{*}{ Grinding/milling techniques } & Samples & $\mathrm{w}(/)$ & $\phi(/)$ & $\mathrm{S}(/)$ & $\rho_{\mathrm{s}}{ }^{*}\left(\mathrm{~g} . \mathrm{cm}^{-3}\right)$ \\
& & & & & \\
\hline & $\mathrm{KM}_{6}$ & 0.096 & 0.672 & 0.253 & 1.246 \\
Knife milling (KM) & $\mathrm{KM}_{2}$ & 0.095 & 0.697 & 0.361 & 1.610 \\
\hline & $\mathrm{IM}_{0.5}$ & 0.093 & 0.745 & 0.450 & 1.665 \\
\hline & $\mathrm{IM}_{0.1}$ & 0.090 & 0.763 & 0.480 & 1.700 \\
\hline & $\mathrm{VBM}_{20}$ & 0.089 & 0.826 & 0.698 & 1.618 \\
Vibro-ball milling (VBM) & $\mathrm{VBM}_{40}$ & 0.086 & 0.827 & 0.809 & 1.629 \\
\hline
\end{tabular}




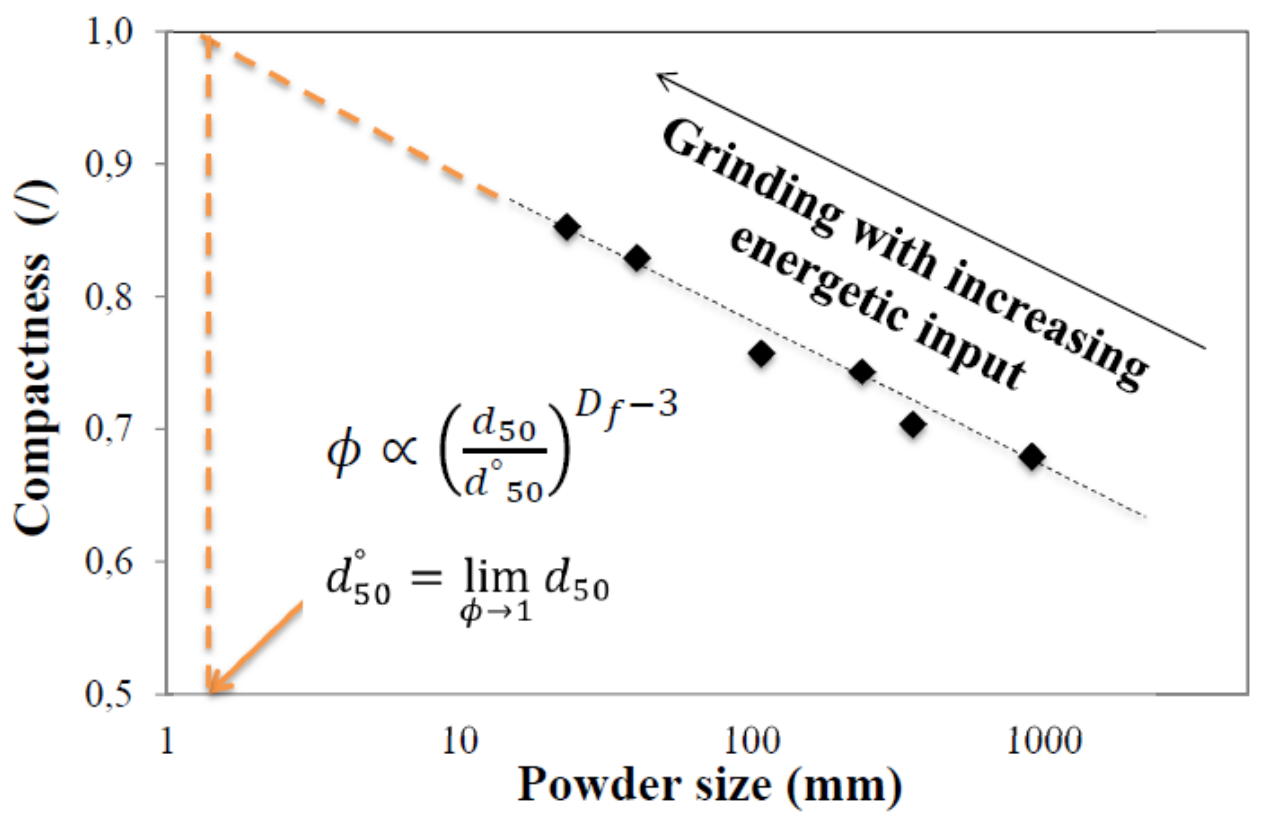

Graphical abstract 


\section{Highlights}

- Grinding facilitate extraction of biomolecules from lignocellulose matrix as straw

- Hydrotextural characterization allows the identification of the grinding mechanisms

- Physical limit of grinding is a characteristic cell thickness deduced from a model 